\title{
Report of the 5th International Congress of Nutritionists
}

\author{
Natasa Sekulic \\ Vocational College, Chemical, Biotechnology and Medicine Department, 24000 Subotica, Srbija
}

\begin{abstract}
A B S T R A C T
The article deals with the importance of the 5th International Congress of Nutritionists held in Zagreb, Croatia. At the ceremonial opening of the congress, all the guests were greeted by Tena Niseteo, MSc, PhD, Organizing Committee Chair and prof. dr. sc. Irene Colic Baric, president of the scientific committee of the congress. The program consisted of workshops, oral presentations, panel discussions and poster sections. What sets this Congress apart from others is the fact that beside nutritionists, experts in the field of medicine, pharmacy, food technology, agronomy, kinesiology and psychology are also joining. The theme of the congress this year was "Sustainable nutrition throughout all ages".
\end{abstract}

Key words: Diet, Nutrition, Multidisciplinary, Congress

Po peti put, održan je Međunarodni kongres nutricionista, koji je ove godine privukao više od 400 posjetilaca i više od 30 uvaženih i uglednih predavača iz Hrvatske i svijeta. Značaj Kongresa je višestruk, a ono što ga posebno izdvaja, jeste činjenica da, pored nutricionista, postoji jasna tendencija okupljanja stručnjaka i iz oblasti medicine, farmacije, prehrambene tehno- logije, agronomije, kineziologije kao i psihologije, čime sve više dobija multidisciplinarni karakter. Krovna tema kongresa ove godine bila je „Održiva prehrana kroz sve životne dobi“ i kao takva, bila je protkana kroz mnogobrojne radionice, predavanja i panel diskusije.

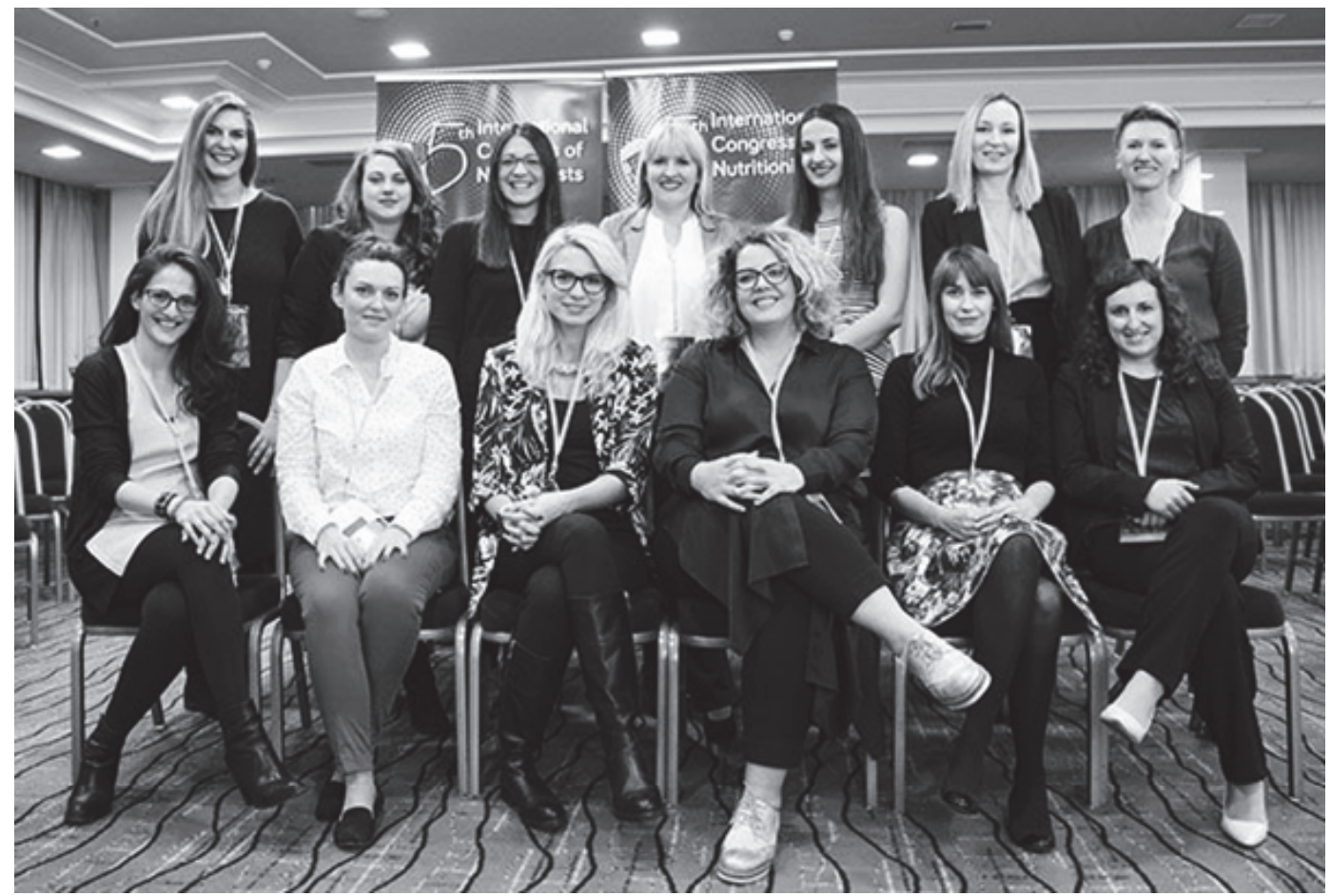

Slika 1. Organizacijski odbor 5. Međunarodnog kongresa nutricionista

Kongres je održan u periodu od 17-19. oktobra 2017. godine, u svečanom i prostranom kongresnom centru hotela „Panorama" u Zagrebu, a organizatori su, kao i prethodnih godina, bili Hrvatski Zbor Nutricionista, Udruga Nutricionizam Balans i Hrvatski Akademski Centar Primijenjenog Nutricionizma. Me- đunarodni partneri Kongresa bili su Slovensko strukovno udruženje nutricionista i dijetetičara (SNDA) i Američko društvo za parenteralnu i enteralnu prehranu (ASPEN), kao i tri domaća partnera: Klinika za dječje bolijesti Zagreb, KBC Split i Udruga studenata PROBION sa Prehrambeno-biotehnološkog fakulteta 
Sveučilišta u Zagrebu. Organizacijski odbor činili su: Nataša Šoštarić, dipl. ing. preh. teh., Dora Babić, mag. nutr., Valerija Bukvić, mag. nutr., Karmen Matković Melki, dipl. ing. preh. teh., Josipa Mađarić, mag. nutr., Marija Petras, mag. nutr, Sara Sila, mag. nutr., Dora Bučan, mag. nutr., Ana Ilić, mag. nutr., Hrvoje Centner mag. nutr., Sanja Cosić, dipl. ing. preh. teh., Maja Gradinjan Centner mag. nutr., Andrea Gvozdanović, dipl. ing. preh. teh. i dr. sc. Tena Niseteo, dipl. ing. preh. teh. - predsednica (Slika 1). Znanstveni odbor, na čelu sa predsjednicom prof. dr. sc. Irenom Colić Barić, činili su: Prof. dr. sc. Daniela Čačić Kenjerić, Prehrambeno tehnološki fakultet, Sveučilište J.J. Strossmayera u Osijeku, Prof. dr. sc. Nataša Fidler Mis, Biotehnički fakultet, Sveučilište u Ljubljani, Prof. dr. sc. Milica Martinović, dr. med, Medicinski fakultet, Sveučilište Crna Gora, Prof. dr. sc. Mauro Serafini, Full Professor of Human Nutrition and Head of the Functional Foods and Metabolic Stress Prevention Laboratory, Teramo University, Doc. dr. sc. Fuad Pašić, dr. med., Univerzitetski klinički centar Tuzla, Doc. dr. sc. Ivana Rumbak, Prehrambeno-biotehnološki fakultet, Sveuči- lište u Zagrebu, Doc. dr. sc. Irzada Taljić, Pedagoški fakultet Sarajevo, Sveučilište u Sarajevu, Dr. sc. Sanja Kolarić Kravar, Ministarstvo poljoprivrede Republike Hrvatske, Dr. sc. Milka Popović, Institut za javno zdravlje Vojvodine, Srbija, Dr. sc. Jasmina Ranilović, znanstvena suradnica, direktorica Sektora za istraživanje i razvoj, Podravka d.d., Dr. sc. Darja Sokolić, znanstvena suradnica, načelnica Odjela za upravljanje podacima i prehranu, Hrvatska agencija za hranu, Mr. sc. Branislava Belović, dr. med., umirovljeni stručnjak Nacionalnog instituta za javno zdravlje, Slovenija i Mr. sc. Miroslav Venus, dr. med., epidemiolog, Zavod za javno zdravstvo Virovitičko-podravske županije ,Sveti Rok“.

Prvi dan Kongresa služio je okupljanju učesnika i protekao je pretježno u znaku radionica, kako onih koje su bile prvenstveno interaktivnog tipa i namijenjene studentima, tako i onih koje su bile namijenjene svim učesnicima, a doticale su se krovne teme Kongresa, koja je bila posmatrana kroz različite aspekte nutricionizma (metode detoksikacije, poremećaje ishrane i druge popularne i aktuelne teme današnjice) (Slika2).

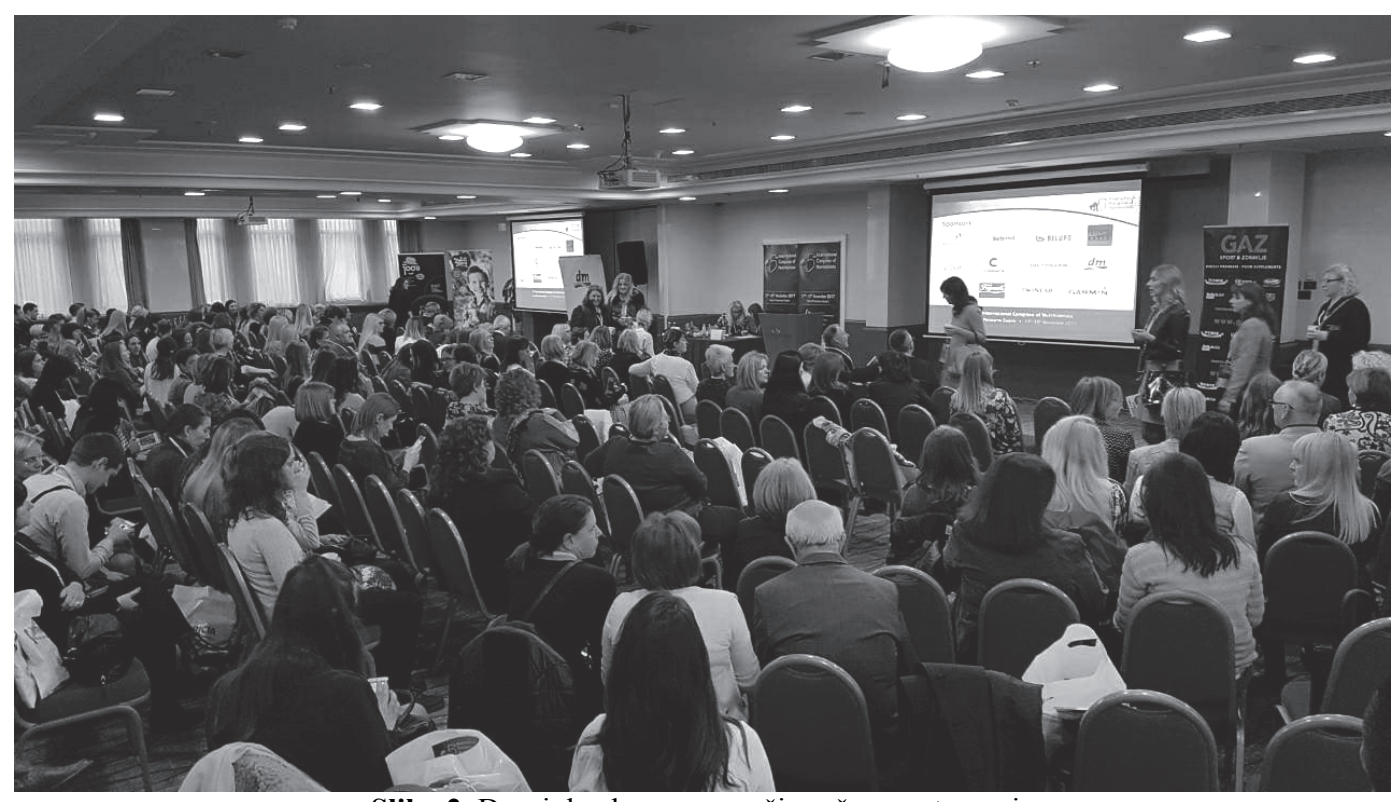

Slika 2. Drugi dan kongresa uoči svečanog otvaranja

Drugi dan je otpočeo svečanim otvaranjem Kongresa, nakon čega su uslijedila plenarna predavanja istaknutih stručnjaka iz različitih naučnih oblasti vezanih za hranu i ishranu ljudi. Dr. sc. Milka Sokolović, direktor sektora za prehranu i zdravlje Evropskog udruženja za informacije o hrani, je putem IKT (Informaciono Komunikacionih Tehnologija) održala predavanje na temu „Zdravija prehrana: Zašto moramo podići glas?“, dok je o tematici prehrane i održive budućnosti govorio ugledni prof. dr. sc. Mauro Serafini sa Univerziteta u Teramu, Italija. „Nauka o ukusima i njihova moguća klinička upotreba“ bila je tema koju je učesnicima na veoma lijep način približio prof. dr. sc. Ole G Mouritsen sa Univerziteta u Kopenhagenu. Danski stručnjak je u svom predavanju istakao značaj upotrebe hrane kojoj je osnova umami ukus.

Poslednji dan Kongresa bio je predviđen za dodjelu svečanih nagrada i pohvala, kao i za proglašenje najboljeg postera $\mathrm{i}$ zvanično zatvaranje kongresa.

U prilog izuzetno dobroj organizaciji i koncepciji Kongresa, govori i činjenica da su, radi lakšeg praćenja u sferama struke i interesovanja, sve sesije bile podijeljene u nekoliko kategorija: prehrana u prevenciji bolijesti, psihologija prehrane, klinička prehrana, suplementacija sportaša, mlijeko i mlječni proizvodi, iza- zovi u prehrani starijih osoba, šećer i so - i prehrana opšte populacije. Tako su se, primjera radi, predavanja iz oblasti kliničke prehrane bavila različitom tematikom - od „fetalnog programiranja“, pa do nutritivnih intervencija kod osoba sa Downovim sindromom. Interesantno je bilo promišljati o tome kako Teorija DO$\mathrm{HaD}$ (Developmental Origins of Health and Disease / Razvojno porijeklo zdravlja i bolijesti) povezuje zdravlje i bolijesti u starosti sa promenama koje su se dogodile tokom fetalnog razvoja (čak i pre koncepcije), što dovodi do zaključka da su moderne bolijesti posledica dvije grupe rizičnih faktora: prve, koja se dešava u najranijoj fazi razvoja i druge grupe, koju u suštini čine rizični faktori okoline kojima smo izloženi tokom kasnijeg života. Predavanje iz ove oblasti održala je prof.dr.sc. Sanja Kolaček voditeljica Referentnog centra za dječiju gastroenterologiju i prehranu Klinike za dječije bolijesti u Zagrebu. Isto tako, veoma je interesantno bilo i predavanje u okviru druge kategorije, koje je ukazivalo na jedan od velikih problema u nutricionizmu, a to je upotreba dodataka ishrani kod sportista. Predavači na ovu temu su ukazali na generalni problem iracionalnog korišćenja dodataka prehrani kod sportista, zbog nedovoljnog znanja o optimalnoj sportskoj ishrani - kako sportista, tako jednako i njihovih trenera. Stručnjaci iz Slovenije kao jedini dugoročni pristup u razrješava- 
nju ovog problema vide usmjereno ili ciljano obrazovanje sportista i njihovih trenera, što bi moglo da podstakne kritičko razmišljanje pojedinaca, a ujedno moglo da dovede i do povećane i pojačane saradnje sportista sa prehrambenim stručnjacima. Najzad, ali ne i najmanje bitno, veliki broj radova na Kongresu koji su se doticali tema edukacije djece, adolescenata i odraslih o bitnim aspektima pravilne prehrane, govorili su u prilog posvećenosti i usmerenosti nutricionista ka podizanju nivoa znanja o prehrani u cilju održanja zdravlja i prevencije hroničnih nezaraznih bolesti.

Pored svega navedenog, čini se u ovom kontekstu važnim istaći i kako je Znanstveni odbor kongresa od svih 35 izloženih i prikazanih, odabrao pet najboljih postera:

- $\quad$ "Prehrana trudnica i dojilja"

Autori: M. Novak, I. Tkalec, M. Vidović

- $\quad$ "Prehrambene navike Roma u Pomurju" Autori: B. Belović, L. Zaletel Kragelj, J. Farkaš Lainščak, S. Tkalec

- $\quad$ "Utjecaj prehrane majke i potomaka na površinu i broj adipocita bijelog masnog tkiva muških potomaka štakora"

Autori: D. Šnajder, Ž. Perić Kačarević, M. Fenrich, N. Bijelić, M. Bakula, R. Radić
- $\quad$ "Procjena unosa energije i hranjivih tvari u osoba smještenih u domove za starije osobe" Autori: M. Gregorić, K. Zdešar Kotnik, I. Pigac

- $\quad$ "Savjetovalište za prehranu u ZZJZ Istarske županije" Autori: O. Dabović Rac, K. Blarežina, H. Mitrović , K. Jelenić, L. Meden, V. Fontana, A. Stojanović;

Svi autori postera imali su usmeno izlaganje, odnosno, odbranu prikazanih radova, nakon čega su svi prisutni učesnici Kongresa glasali za najbolji poster. Od pet prethodno navedenih, upravo je poster na temu "Uticaj prehrane majke i potomaka na površinu i broj adipocita belog masnog tkiva muških potomaka štakora" proglašen za najbolji poster Kongresa. Autori ovog naučno-istraživačkog rada su došli do zaključka da promena dijete nakon rođenja i laktacije dovodi do hiperplazije adipocita subkutalnog i epididimalnog masnog tkiva, dok masna prehrana uzrokuje hiperplaziju adipocita perirenalnog belog masnog tkiva. Matija Frenrich, jedan od autora ovog postera, nagrađen je sa 10.000 kuna za odlazak na edukaciju po želji u 2018. Godini (Slika 3).

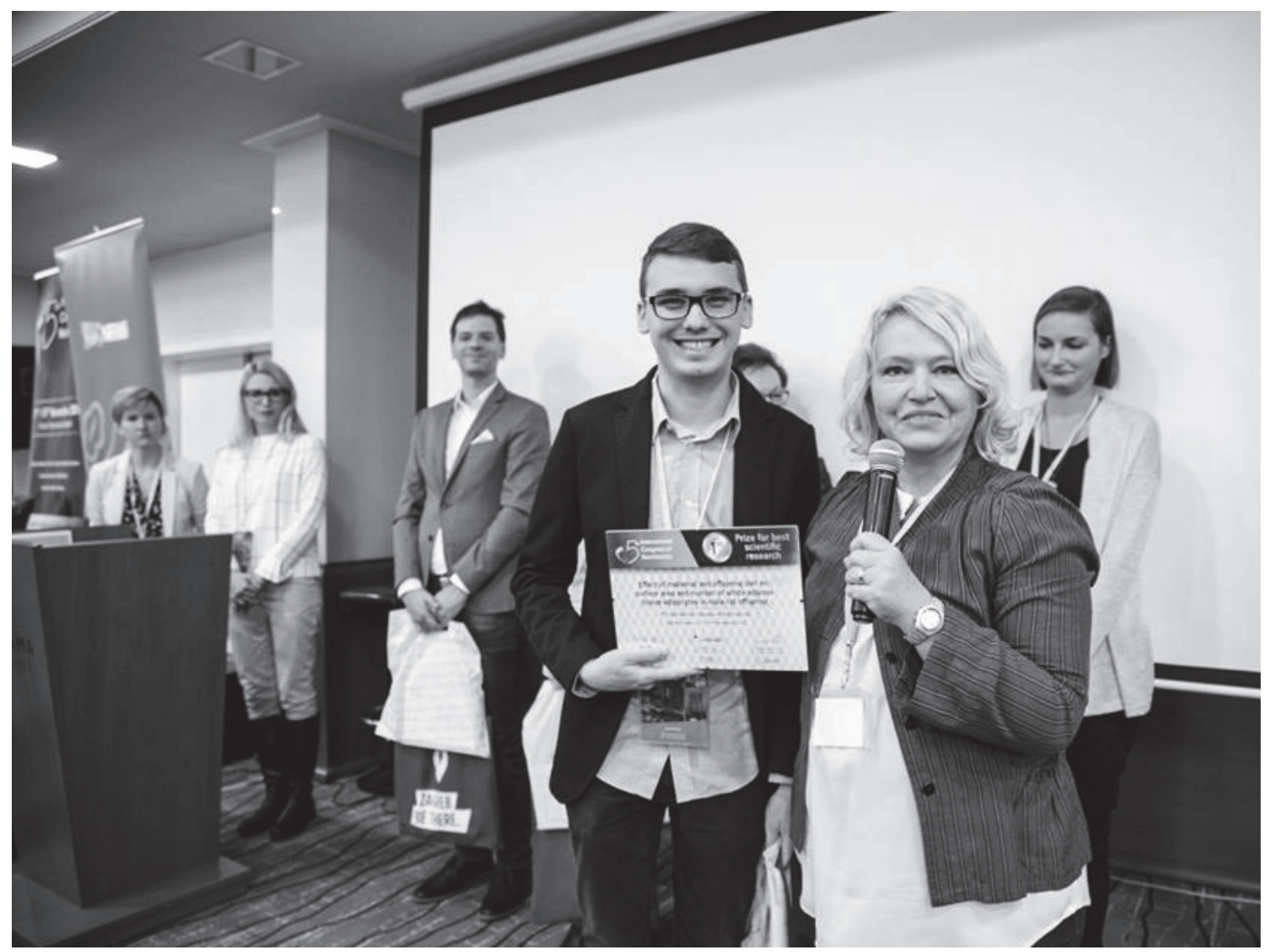

Slika 3. Dodela nagrade za najbolji poster tokom 5. Međunarodnog kongresa nutricionista

Osim izuzetne važnosti u vidu doprinosa prehrambenoj struci i daljem razvoju naučno-istraživačkih radova u sferi nutricionizma, Kongres je imao veliki značaj i u smislu pružanja mogućnosti za nova poslovna poznanstava i razmene ideja, sa ciljem zajedničkih (bilo naučno-istraživačkih ili preduzetničkih) poduhvata. Iz ovog razloga su, tokom pauza između predavanja i u okviru predviđenog slobodnog vremena, često bili organizovani kraći ili duži promo-kanapei i drugi oblici veoma interesantnih, zanimljivih i interaktivnih "gastro-dešavanja", koji su omogućili učesnicima da u neformalnoj i prijatnoj atmosferi razmijene iskustva i stupe $u$ neposrednije kontakte jedni sa drugima.

6. Međunarodni kongres nutricionista biće održan od 26. do 28. oktobra 2018. u Zagrebu u organizaciji Hrvatskog Saveza Nutricionista. 


\section{R E F E R E N C E S}

Hrvatski akademski centar za primjenjeni nutricionizam. Hrvatski akademski centar za primjenjeni nutricionizam. (2017). Knjiga sažetaka 5. Međunarodnog kongresa nutricionista. Zagreb.

Dostupno 15.12.2017. na: http://www.2017.kongresnutrici-

5. Međunarodni kongres nutricionista. (13.12.2016). Zagreb: onista.com

N. Sekulic

Vocational College, Chemical, Biotechnology and Medicine Department, Banijska 67, 2400 Subotica, Serbia e-mail: natasa25m@gmail.com 